\title{
DEONTOLOGÍA PROFESIONAL Y LA PROFESIÓN DE ABOGADO
}

\author{
Jorge F. Malem Seña \\ Universidad Pompeu Fabra
}

\begin{abstract}
iborio HierRo es un buen conocedor del derecho, de su filosofía y de las prácticas profesionales que lo utilizan como una de sus herramientas básicas. Tal vez su paso por el Ministerio de Justicia ${ }^{1}$ le haya permitido tener una visión de conjunto de esas prácticas, y de los profesionales que las realizan, que no es nada común en nuestro entorno.
\end{abstract}

Que ese conocimiento no sea común se puede deber a varios factores. El primero, y al que prestaré atención, es la dificultad que existe al tratar de definir qué es una profesión y, por extensión, cuáles son las profesiones jurídicas. Como el propio Liborio HIERRO admite, el concepto mismo de profesión es ya controvertido ${ }^{2}$. Su caracterización depende muchas veces del punto de vista del cual se parte o de los objetivos a los que se quiere llegar. Y la delimitación de cómo ha de entenderse las profesiones jurídicas no ha resultado históricamente inmune a esta discusión. La cuestión se complica, aún más si cabe, si se toma en consideración que los juristas, entendidos en un sentido amplísimo como profesionales del derecho, han desarrollado una serie de actividades cuyo parecido entre sí es solo el de tener un cierto aire de familia. Todo esto, y otros elementos a los que no prestaré atención aquí, torna complicado hablar de las profesiones jurídicas sin más.

En cualquier caso, a los efectos de evitar disputas puramente verbales, entenderé que el concepto de profesión aplicable a la idea de profesión jurídica ejemplificada en la del abogado hace referencia a las siguientes diez características³:

1. La actividad profesional se basa en conocimientos científicos y técnicos. De hecho, el conocimiento y la formación de los profesionales se encuentra altamente estandarizado. Un profesional de la abogacía, como el resto de profesionales, trata de aplicar estructuras teóricas para resolver los problemas que se le plantean en el mundo real. De hecho, la superioridad de los profesionales para superar dificultades sobre quienes no lo son se basa en la posesión de un conocimiento técnico superior.

2. Por esa razón, las profesiones exigen cierto periodo de aprendizaje y de adiestramiento. Las profesiones clásicas como el derecho y la medicina requieren previo a

\footnotetext{
1 Ocupó el cargo de subsecretario de Justicia entre los años 1982 y 1990.

2 Vid. L. HierRo, «Las profesiones jurídicas: una visión de conjunto», Sistema, núm. 37, 1997, 27 y ss.

3 Me referí a estas cuestiones de un modo más extenso en La profesionalidad judicial, México, Fontamara, 2009.
} 
su ejercicio que se estudie durante cuatro, cinco o más años en un centro universitario y que se cumplimente un currículo muchas veces abultado.

3. En este sentido, las profesiones, como las jurídicas, son actividades que tienen un componente esencialmente intelectual. No es que un profesional haya de excluir por completo el trabajo manual o físico, piénsese en un médico cirujano, pero este ha de ser un instrumento del intelecto, no ha de constituir el centro de su actividad.

4. Las profesiones - los profesionales- prestan un servicio a la sociedad que es esencial y es único ${ }^{4}$. Dicho servicio es esencial porque ninguna sociedad desarrollada podría desprenderse de él sin grave pérdida. Basta pensar en lo que sucedería si no existiera la profesión médica, por ejemplo .

Es un servicio único, además, porque cada profesión reclama para sí la exclusividad de la práctica que sus miembros realizan. Cada profesión pretende detentar el monopolio sobre su propia actividad. Esto explicaría que en prácticamente todas las latitudes, el intrusismo profesional sea generalmente perseguido y reprimido.

5. Los profesionales ejercen su actividad con un alto grado de autonomía. Esto surge de las características 1 y 2 arriba mencionadas. La relación que existe entre el profesional y quien solicita sus servicios es de una clara asimetría producida por las diferentes habilidades, capacidades o competencias que el profesional tiene para analizar y solucionar los problemas planteados. Por ello, los profesionales deben seguir su propio juicio o criterio al resolver las cuestiones que llegan a su conocimiento. Si así no lo hicieran, ¿qué sentido tendría consultar a un profesional? ${ }^{6}$.

6. Las profesiones implican que quienes las ejerzan asuman su responsabilidad por los actos que autónomamente decidieron realizar. Esto es, los profesionales siempre tienen que estar dispuestos a dar cuenta de sus acciones. En nuestras sociedades prácticamente nadie discute que los profesionales deben ser responsables tanto desde un punto de vista técnico como moral y jurídico.

7. El ejercicio de las profesiones constituye también una forma de obtener recursos pecuniarios, de modo tal que se transforma en un medio de vida. Esto ha servido para distinguir al profesional del aficionado. Ganar dinero es un aspecto del profesionalismo. Pero esto no ha de llevar al error de considerar que las profesiones son exclusivamente un instrumento para obtener ganancias económicas o para lograr estatus social.

8. Las profesiones deben ser ocupadas por personas con vocación. Esto es, por individuos que tienen la pretensión de hacer de su actividad su estilo de vida, con la intención de practicarla de un modo continuado en el tiempo, con un claro sentido de permanencia en ella. Esto permite diferenciar a los profesionales de aquellos que hacen una misma actividad pero de una forma aislada o puntual.

9. Las profesiones se estructuran a través de organizaciones o instituciones que establecen normas básicas para su ejercicio. La profesión organiza y disciplina a sus

4 Vid. J. GonZÁLEZ ANLEO, «Las profesiones en la sociedad corporativa», en J. L. FERnÁNDEZ FERnÁnDeZ y A. Hortal Alonso (comps.), Ética de las profesiones, Madrid, Universidad Pontificia Comillas, 1994, 26.

5 Vid. M. BAYLES, Professional Ethics, Wadsworth Publishing Co., 2. ${ }^{a}$ ed., 1989, 8.

${ }^{6}$ Ibid., 8. 
miembros. La profesión establece, por ejemplo, qué criterios han de regir la práctica profesional, cuál debe ser la relación entre los diferentes profesionales y cuáles deberían ser las vinculaciones entre estos y quienes solicitan sus servicios o se someten a su competencia. Los colegios de abogados constituyen un claro ejemplo de cómo se disciplina a sus miembros. Y su deontología profesional asegura qué normas han de regir en el cometido de la tarea del abogado.

10. Por ese motivo, las profesiones exigen que sus miembros posean una cierta credencial donde se ponga de manifiesto su competencia; esto es, donde se le reconozca su capacidad para operar dentro de un determinado ámbito. A veces esta credencial consiste en un título universitario, en otras ocasiones en la certificación de un colegio profesional, etcétera ${ }^{7}$.

La satisfacción, o no, de estas notas esenciales permitiría distinguir, tal como lo hace Michael BAYLES, entre las personas que son profesionales y aquellas que desarrollan simplemente una ocupación. Y entre los profesionales y quienes solo se comportan como técnicos. En el primer caso, bastaría con señalar que aquellas tareas que no requieren una preparación adecuada, que no exigen periodos de estudios específicos o no necesitan un título habilitante no podrían ser consideradas profesiones, tal como es el caso de una secretaria o de un comerciante. En el segundo caso, la diferencia radica en que el técnico carece de la autonomía propia de los profesionales, su tarea es meramente instrumental ${ }^{8}$.

Naturalmente, los elementos mencionados son receptados en grados diversos en las distintas profesiones. Ello contribuye a la discusión acerca de si una determinada práctica puede o no ser considerada una profesión o a catalogar ciertas actividades como semiprofesionales. El abogado y la práctica de la abogacía cumplen sobradamente con todos estos requisitos y, por tanto, nadie debería dudar de que es un auténtico profesional.

Ahora bien, como adecuadamente señala Liborio HIERRO, la práctica de las profesiones jurídicas, y de la abogacía, se ha desarrollado alrededor de los conflictos, para evitarlos o para resolverlos. Esta práctica se estructura, básicamente, a través de su sometimiento estricto al derecho. Por ese motivo, es posible reconstruir sus funciones diciendo que un abogado hace propuestas para la elaboración de normas jurídicas dentro de los parámetros admitidos por el derecho, cuando redacta un contrato que otros firmarán, por ejemplo, o hace aplicación del derecho, verbigracia, en los procesos de judicialización del conflicto?

Esto supone que el abogado asume un compromiso institucional básico. Y es que está profesionalmente vinculado a la legalidad. Esto es, no debe realizar acciones ilegales, ni tampoco asesorar o recomendar a su cliente que actúe ilegalmente. Si así no

7 Vid. E. Hughes, «Professions», en J. Callaham (ed.), Ethical Issues in Professional Life, Oxford, Oxford University Press, 1988, 31.

8 Vid. M. BAYLES, op. cit., 10 y ss.

9 Vid. L. Hierro, «Las profesiones jurídicas. Una visión de conjunto», op. cit., 30. Según sus palabras, «diremos que son profesiones jurídicas aquellas cuya actividad habitual consiste en la elaboración técnica de normas jurídicas, su aplicación y la prevención y resolución de conflictos jurídicos. Ello significa que lo característico de las profesiones jurídicas sería la elaboración y aplicación de normas jurídicas». 
lo hiciera, en cualquiera de los dos supuestos, quedaría fuera de los márgenes de su profesión. En cuanto a la aceptación de la legalidad, el abogado no se distingue del juez, ni de los fiscales. En este sentido, el ideal de la profesión de la abogacía exige que el abogado sea un seguidor de normas jurídicas.

Un tipo de esas normas jurídicas garantiza el derecho de defensa de los ciudadanos ante la intromisión que pretenden ilegítima del Estado, de otros conciudadanos, de empresas o de personas jurídicas. En estos supuestos, los ciudadanos tienen derecho a autodefenderse o bien a solicitar una defensa técnica que se incardine a través del abogado. Esto hace pensar que el abogado asume los intereses del cliente y pone sus conocimientos y habilidades a su disposición. El abogado se presentaría así como un partisano que apoya, patrocina y defiende los intereses de un tercero sin importar cuáles sean estos. Su parcialidad quedaría así justificada, a diferencia de la profesión de juez que exige imparcialidad ${ }^{10}$. La tarea del abogado sería verter en términos técnicos las preferencias, intereses, pretensiones o derechos de sus clientes ${ }^{11}$.

Nada habría que reprochar, pues, si un abogado defiende un determinado punto de vista hoy y al día siguiente uno contrario o contradictorio. El abogado pone su ciencia, no su conciencia, al servicio del cliente. Y daría la impresión que las normas deontológicas de la abogacía, al menos en los países de nuestro entorno, receptan esta forma de presentar su actividad profesional.

Pero pensar que los abogados están vinculados exclusivamente a los intereses del cliente, aun en el ejercicio liberal de la profesión, es un error. Incluso en este contexto, los abogados asumen una serie de compromisos institucionales que deviene de su aceptación de la legalidad. Solo a efectos ejemplificativos y sin ningún ánimo de exhaustividad. Los abogados no deberían pleitear en todas las causas, tal como suelen hacerlo actualmente, sin tener al menos alguna pretensión con visos de plausibilidad, aunque así se lo pidiera su cliente. No deberían atentar contra la eficacia del proceso, tal como suelen hacerlo actualmente, interponiendo «chicanas» para dilatar el juicio, aunque de ese modo mejoraran la posición de su patrocinado. Y aún si se aceptara que el acusado, en un proceso penal, tiene el derecho constitucional a mentir, el abogado no debería enseñar a su defendido a mentir. La parcialidad del abogado que así constreñida por los límites impuestos por el derecho.

Alguien podría decir que estas acciones que he calificado deónticamente como prohibidas estarían permitidas o incluso serían obligatorias desde el punto de vista deontológico. Si la técnica enseña qué mecanismos son idóneos para alcanzar determinados fines y señala que pleitear indiscriminadamente, «chicanear» o mentir son medios adecuados para la defensa de sus patrocinados, no habría dudas acerca de la legitimidad de tales comportamientos. La moral profesional del abogado le eximiría no

${ }^{10}$ Esta idea de parcialidad del abogado frente a la exigencia de imparcialidad del juez es puesta de manifiesta repetidamente por L. HIERRO.

${ }_{11}$ En palabras de L. HierRo, «Por lo que se refiere a los abogados es difícil sustraerse a la convicción dominante de que la relación del abogado con el cliente consiste, en cualquier orden de actividad, en optimizar los intereses del cliente dentro del marco de posibilidades legales». Vid. «¿Se puede pleitear? Platón, Garzón y la deontología de los abogados», Doxa, núm. 30, 125. 
solo del cumplimiento de los mandatos de la moral crítica o esclarecida sino también de ciertos encorsetamientos procesales ${ }^{12}$.

Esto supone que existe una moral profesional diferente y superior a la moral crítica y que al asumir una determinada profesión se está obligado a seguir las obligaciones profesionales y no las normas de la moral crítica. Las supuestas reglas técnicas involucradas oficiarían como razones operativas que activarían las normas profesionales. Lo «bueno técnico» superaría a lo «bueno moral» a través de las reglas deontológicas. No reproduciré aquí el debate sobre la naturaleza de las morales profesionales y sus relaciones con la moral crítica sobre las que existe una abundante bibliografía ${ }^{13}$. Asumiré dogmáticamente que los profesionales están constreñidos por la moral crítica y que su rol social no les excusa de su cumplimiento. Que sean responsables moralmente por lo que hacen y no únicamente en sentido técnico así parece mostrarlo.

El abogado como cualquier otro profesional es moralmente responsable por los casos que patrocina por una razón adicional. Admitido que escoge voluntariamente la defensa de determinados intereses mientras rechaza otros, y que su labor profesional, sobre todo en un proceso judicial, está vinculado con la posibilidad de apelar al uso de la violencia estatal para hacer valer los intereses patrocinados, debe dar cuenta de sus gestiones y no solo en sentido técnico. La afirmación de que el abogado no pone su conciencia, sino únicamente su ciencia, al servicio del cliente debería ser matizada en este punto.

Y por último, hay otra forma de rechazar la idea de que el vínculo fundamental del abogado en el ejercicio liberal de su profesión sea con la defensa irrestricta de los intereses de su cliente. Y es que no se puede asumir que la norma que le autoriza a representarlos legalmente siempre será superior a otras con las que pudiera colisionar. De ahí que también tenga límites jurídicos a su acción.

Como sostiene Liborio HIERRO, está permitido pleitear por otros, pero — yo agregaría- con muchos límites.

${ }^{12}$ Es verdad que un abogado con experiencia siempre puede presentar los casos que asume con ciertas dosis de plausibilidad, puede plantear incidentes procesales aprovechándose de los mecanismos legales a su disposición o puede asesorar a sus clientes o testigos acerca de las distintas consecuencias jurídicas que tiene para los implicados decir la verdad o asumir un relato no concordante con la realidad sin que parezca que su litigancia sea maliciosa, que colabora o provoca activamente dilaciones indebidas o que enseña a mentir. Pero estas apariencias no son suficientes para ocultar lo que realmente hacen.

${ }_{13}$ Liborio HiERRO se ha referido a estas cuestiones en diversos trabajos citados en esta sede. 